\title{
Between Attraction and Interdiction: Smartphone and Internet
}

\author{
Elena Cocoradă* \\ Department of Psychology, Transilvania University, Romania
}

Submission: August 27, 2018; Published: September 07, 2018

*Corresponding author: Elena Cocoradă, Faculty of Psychology and Education Sciences, Department of Psychology, Education and Teacher Training, Transilvania University of Brasov, Eroilor nr. 29, 500036, Brasov, Romania, Tel: 40742053301; Email: elena.cocorada@unitbv.ro

\section{Abstract}

Smartphone has numerous benefits and negative effects being between attraction and interdiction. Empirical research provides data collected on populations around the world that indicated different prevalence of addiction or only a problematic use. Prohibitions on smartphone use have occurred in some countries. Managing the addiction risk and dangers imply rules of use, understanding of the contradictory aspects and improving users self-control.

\section{Daily Observations}

In the real world, I'm more and more confronted with worrying images: the image of buses or trains in which passengers lean over their personal phones, smiling, frowning, neglecting the neighbors, landscape, and surrounding events; or the image of two young, probably in love, face-to-face at the same pub table, which buzz the smartphone, remaining everybody in his world. I was also told about teenagers who, during the dinner, tap the phone with one hand and eat with another.

\section{Recent Studies}

Smartphone, in opposition with classical mobile phone, support various functions based on Internet, as access to e-mailing, messaging, social networks, chatting or video gaming. This access is just anytime, and almost anywhere. The benefits are numerous: helping by educational applications, looking for exciting activities, promoting healthy behaviors as body weight or alcohol use problems management, disseminating and acquiring information in crisis situations [1,2]. extending communications and improving connection to significant others, contributing to solve stressful situations and improving psychological well-being $[3,4]$. being symbol of higher social status [5]. satisfying the needs for favourable self-presentation and autonomy [6]. These opportunities develop positive attitude towards the smartphone and increase the attraction. Number of hours spent using them, daily frequency of use, and number of messages sent are mediators for smartphone dependence. Use and attraction become risk factors.

Moderated use of smartphone is an advantage, but impulse to repeatedly activities brings him close to substance addiction
[7]. The negative effects occur with excessive and pathological use: poor quality of sleep or sleep deprivation, depression, anxiety and stress [8]. reduced physical activity and increased of fat mass [9]. mobile phone aggression or victimization [10]. distracted from learning and driving motor vehicles, reduced face to face interaction and improved anxiety/ fear about missing out technologies [11]. Adolescents and young adults, more curious, with increased need for independence and seeking instant gratifications, engage in different risk behaviors in real and virtual space, but the threats and consequences always remain real. Numerous empirical researches provide data collected on populations around the world that indicate the prevalence of addiction or only a problematic use. A cross-cultural empirical survey on smartphone dependence in the European sample of young adults, 18-29 years, has identified $11.54 \%$ prevalence [12]. In our study developed too in a European country [13]. prevalence of addiction is higher, $26.92 \%$, for a sample of high school and university participants, being more accentuated for youngest. A recent study in Indian sample identified a higher prevalence, $33.3 \%$, out of a total of $87 \%$ of participants, who were smart phone users [8].

Among Chinese undergraduates, the reported prevalence of problematic use of smartphones was $21.3 \%$ [14]. Prevalence vary by age, gender, cultures, geographies, depend too on screening and diagnostic tools and research decades [15-18]. Beyond the variation of contexts, instruments or samples, participants recognize the existence of symptoms, most of studies being based on self-reported assessment. DSM-V highlighted the prevalence rates of substance use disorder in individuals aged between 18 


\section{Global Journal of Addiction \& Rehabilitation Medicine}

and 24 [17]. The age of highest smartphone addiction risk is smaller in our study, 15-19 years [13]. but studies are needed on other samples. Consecutively, parents and teachers are on alert, and the World Health Organization (2015) considers excessive smartphone use as a public health problem. Knowing and understanding this complex, ambivalent picture and managing your one behavior are difficult for many teens.

\section{Do Several Categories of Addiction or One Exist?}

Although some studies reveal differences, we wonder if there are addiction toward the Internet, addiction toward the computers, addiction toward the smartphone, or addiction toward the electronic games. Smartphone, laptop or desktop computer are only electronic devices, technically they are very similar. By changing the device, excessive use and negative consequences remain. Additionally, the smartphone is not only a communication device (as mobile phone) it is a powerful portable computer [14]. and can be used as a computer to surf the Web. Not the smartphone or computer as objects they attract, but their apps, based on the Internet. Threat in the smartphone looks more pronounced compared with the laptop and desktop computer due to its highest portability and ease of use. Although there are some differences resulting by software incompatibility, peripherals and the complexity of skills, in our opinion, all these dependences can be approached in the same category. Would the term 'behavioral addictions in virtual space' (BAVS) be more appropriate as umbrella concept, or the term 'internet use disorders' proposed by WHO [18].

\section{From Attraction to Interdiction}

Prohibitions on smartphone use have occurred in some countries or are about to occur. See e.g. France, that has been interdicted smartphone and all internet-connected devices use in colleges and high schools for the students under the age of 14 . But addiction also occurs at older ages, and for adolescents, the interdiction itself may increase the attraction. The prohibition can be dangerous if it is strict and isolated. An honest presentation for adolescents of benefits of moderate use and dangers of abusive use should complement the 'rules of use'. But understanding of the contradictory aspects and their emotional acceptance are not certain. It could be simultaneous with the development of self-control capacity and critical thinking. It is an opportunity that high consciousness is not associated with smartphone addiction. In addition, meta-analytic synthesis showed that the higher levels of conscientiousness were directly and significantly related to health across the span [19]. selfdiscipline and deliberation [20]. The importance of self-control has also been highlighted with respect to substance addiction [17]. because childhood self-control predicts physical health, substance dependence, personal finances, early mortality, psychiatric disorders, or unemployment. Fortunately, children's self-control effects are not related to their intelligence, social economic status and adolescence mistakes [21]. Being under both genetic and environmental influences, self-control can be changed. Children's self-control programs have been developed and favorable evaluated [22].

\section{References}

1. Zhang MWB, Ho CSH, Ho RCM (2014) Methodology of development and students' perceptions of a psychiatry educational smartphone application. Technology and Health Care: Official Journal of the European Society for Engineering and Medicine 22(6): 847-855.

2. Zhang MWB, Fang P, Ho RCM (2016) Global outreach and user preferences of a smartphone application developed for drinkers. Technology and Health Care: Official Journal of the European Society for Engineering and Medicine 24(4): 495-501.

3. Al-Barashdi H, Bouazza A, Jabur N, Zubaidi A (2015) Smartphone gratifications among Sultan Qaboos University undergraduates: A mixed-approach investigation. British Journal of Education, Society \& Behavioural Science 10(1): 1-17.

4. Park N, Lee H (2012) Social implications of smartphone use: Korean college students' smartphone use and psychological well-being. Cyberpsychology, Behavior, and Social Networking 15(9): 491-497.

5. Mayudia N, Mothar M, Musa P, Hassan BA, Salleh P, et al. (2013) The Importance of Smartphone's Usage Among Malaysian Undergraduates. IOSR Journal of Humanities and Social Science 14(3): 112-118.

6. Ryan T, Chester A, Reece J, Xenos S (2014) The uses and abuses of Facebook: A review of Facebook addiction. Journal of Behavioural Addictions 3(3): 133-148

7. Batta A (2018) Addiction-How and Type. Glob J Add \& Rehab Med 5(2): $1-3$.

8. Soni R, Upadhyay R, Jain M (2017) Prevalence of smart phone addiction, sleep quality and associated behavior problems in adolescents. International Journal of Research in Medical Sciences 5(2): 515-519.

9. Kim SE, Kim JW, Jee YS (2015) Relationship between smartphone addiction and physical activity in Chinese international students in Korea. Journal of Behavioral Addictions 4(3): 200-205.

10. Nicol A, Fleming MJ (2010) i h8 u: The Influence of Normative Beliefs and Hostile Response Selection in Predicting Adolescents' Mobile Phone Aggression-A Pilot Study. Journal of school violence 9(2): 212231.

11. Przybylski AK, Murayama K, DeHaan Cody R, Gladwell V (2013) Motivational, emotional, and behavioral correlates of fear of missing out. Computers in Human Behavior 29: 1841-1848.

12. Lopez Fernandez O, Kuss DJ, Romo L, Morvan Y, Kern L, et al. (2017) Self-reported dependence on mobile phones in young adults: A European cross-cultural empirical survey. Journal of Behavioral Addictions 6(2): 168-177.

13. Cocoradă E, Maican CI, Cazan AM, Maican AM (2018) Assessing the smartphone addiction risk and its associations with personality traits among adolescents. Children and Youth Services Review 93: 345-354.

14. Long J, Liu TQ Liao, YH, Qi C, He HY, et al. (2016) Prevalence and correlates of problematic smartphone use in a large random sample of Chinese undergraduates. BMC Psychiatry 16(1): 408.

15. Haug S, Castro RP, Kwon M, Filler A, Kowatsch T, et al. (2015) Smartphone use and smartphone addiction among young people in Switzerland. Journal of Behavioral Addictions 4(4): 299-307.

16. Ling R (2001) Adolescent girls and young adult men: Two sub-cultures of the mobile telephone. Telenor Research and Development R\&D Report, p. 34.

17. American Psychiatric Association (2014) Diagnostic and Statistical Manual of Mental Disorders. 
18. WHO (2015) Public Health Implications of Excessive Use of the Internet, Computers, Smartphones and Similar Electronic Devices, Meeting report, p. 27-29.

19. Kern ML, Friedman HS (2008) Do Conscientious Individuals Live Longer? A Quantitative Review. Health Psychology 27(5): 505-512.

20. Costa PT, McCrae RR (1998) Six approaches to the explication of facetlevel traits: Examples from conscientiousness. European Journal of Personality 12: 117-134.
21. Moffitt TE, Arseneault L, Belsky D (2011) A gradient of childhood selfcontrol predicts health, wealth, and public safety. Proc Natl Acad Sci USA 108(7): 2693-2698.

22. Greenberg MT (2006) Promoting resilience in children and youth: Preventive interventions and their interface with neuroscience. Annals of the New York Academy of Sciences 1094: 139-150.

\section{Your next submission with Juniper Publishers will reach you the below assets}

- Quality Editorial service

- Swift Peer Review

- Reprints availability

- E-prints Service

- Manuscript Podcast for convenient understanding

- Global attainment for your research

- Manuscript accessibility in different formats

( Pdf, E-pub, Full Text, Audio)

- Unceasing customer service

Track the below URL for one-step submission https://juniperpublishers.com/online-submission.php 